\title{
Perceived organizational support and job satisfaction: a moderated mediation model of proactive personality and psychological empowerment
}

\author{
Annum Tariq Maan ${ }^{1}$, Ghulam Abid ${ }^{1}$, Tahira Hassan Butt ${ }^{*}$, Fouzia Ashfaq ${ }^{2}$ and Saira Ahmed ${ }^{3}$
}

\begin{abstract}
Drawing on social exchange theory, the purpose of this study is to examine the mediating role of psychological empowerment and moderating role of proactive personality in the relationship between POS and job satisfaction. The data were collected from 936 employees working in various manufacturing and service sectors by using selfreport survey questionnaires by employing time-lagged cross-sectional study design. The study findings demonstrate that POS positively influenced psychological empowerment and job satisfaction. Moreover, it is also revealed that the relationship between POS and job satisfaction is weaker when employees' proactive personality is higher rather than lower. The findings of the current study pose a framework for organizational representatives of both service and manufacturing industries to strengthen individual psychological empowerment and job satisfaction by offering organizational support to those individuals who are less proactive.
\end{abstract}

Keywords: Perceived organizational support (POS), Social exchange theory, Job satisfaction, Psychological empowerment, Proactive personality

\section{Introduction}

A long-lasting employment bond comprises positive social exchange approaches in employee-employer relationship whereupon the needs of both parties are addressed [40]. In the exchange relationship, the employer is worried about the employees' devotion, engagement and trustworthiness toward them, while employees are conscious about whether their employer is keeping their promises by caring their well-being [48, 61]. The theory of organizational support and construct of perceived organizational support (POS) was developed by Eisenberger and his research fellows in $[26,27]$ using social exchange theory $[15,37,40]$. POS is defined as the perception of employees about the degree to which

\footnotetext{
*Correspondence: tahirabutt433@hotmail.com

${ }^{1}$ School of Business Administration, National College of Business

Administration and Economics, Lahore, Pakistan

Full list of author information is available at the end of the article
}

their contributions at organizations are valued, which implies that their associated well-being is given full consideration $[5,26,61]$. The organizational support theory states that individuals form POS, a universal faith that their employer has an advantageous or a disadvantageous inclination toward them [40,61]. Literature also confirms that individuals' POS helps boost their obligations toward organization in order to reciprocate favorably. Furthermore, they also want to satisfy their socioemotional needs and incorporate organizational affiliation into their social identity [21, 29]. In addition, extant literature has shown that individuals' POS enhances both in-role performance such as goal attainment and extrarole performance such as helping and supportive behavior toward coworkers [29].

By utilizing social exchange theory as its grounding, researchers have begun to study POS in interpersonal connections with organizations and recognized it as a 
vital ingredient in subordinate-manager relations [65]. Meta-analysis conducted by Rhoades and Eisenberger [61] revealed the favorable treatments such as rewards from the organization, beneficial working conditions and fairness received by employees are directly linked to POS. Moreover, POS promotes auspicious outcomes such as high job satisfaction, lower turnover, enhanced dedication, positive emotions and better performance [77]. Multi-foci methods to social exchange have highlighted the significance of many sources of support, according to which individuals develop distinct give-and-take relationships with different organizational objectives [51]. The positive association of POS with job satisfaction, performance, organizational commitment and turnover intention has gained attention in number of employeeorganization-related studies [30, 74]. Similarly, the outcomes that are relevant to organizational support are job satisfaction, innovative work behavior, learning goal orientation, core self-evaluations and organizational commitment $[1,59,71,74,78]$. Furthermore, the literature reveals that organizations achieve favorable outcomes if workers feel superior treatment within the organization [74].

Based upon the theoretical perspective of social exchange theory, the current study proposes that psychological empowerment influences the behavior of employees by facilitating them in preserving high-quality relationships. We suggest that psychological empowerment works as the intervening variable that links the POS with the job satisfaction. Psychological empowerment is defined as the perception of employees regarding the degree of their competence, influence and autonomy toward work environment and meaningfulness of their job [62]. It is the procedure by which employees achieve mastery and control in their lives, and develop a sense of critical understanding toward dealing their situation [12, 55]. Researchers Chang and Liu [17], Savery and Luks [63], Laschinger and Finegan [50] contended that empowered employees at the workplace have increased personal, political and interpersonal powers that enhance their physical and mental health. Thus, another purpose of the current study is to investigate the linkage between perceived organizational support and job satisfaction via the mediating role of employees' psychological empowerment. However, the understanding of the work context that enables empowerment has significant practical and theoretical implications [16], but we do not know how and why this is the case. This research also examined whether and how proactive individuals might be a boundary condition for the impact of POS on psychological empowerment. In addition, it explored how the overall mediation process differs under various proactive personality levels.
Proactive personality refers to the tendency of individuals to take initiatives for establishing a positive environment $[10,22,70]$. Usually, people with a proactive personality are able to create positive change in the workplace environment irrespective of the hurdles and constraints faced by them [62]. Proactive personality research shows that proactive behavior influences meaningful changes in the workplace setting [10, 44]. Researchers contend that proactive individuals are most probably ready for employment-related changes, given their predisposition to identify and respond to the job opportunities and make such changes that match with their interests at job [44, 68]. In support of this reason, experiments have shown that proactive individuals can effect vocational adaptability through situations and samples $[38,44,53,68,69]$. However, there is vague understanding of the underlying mechanisms concerning how these effects arise. Examining these mechanisms probably offers counselors and psychologists with substitutes for intervention in the future [44]. For example, from these types of mechanisms, these experts probably gain comparatively advanced understandings concerning whether and how proactive employees feel psychologically empowered.

Psychological empowerment represents an employee's active and lively orientation to their respective role assigned at workplace, whereby empowered employees see their work environment as somewhat which can be shaped by their actions [66], which arouses their creative behavior [41,79], whereby it serves as a mediator that transmits the impact of proactive individuals to job satisfaction. Thus, this study aims at exploring how contextual characteristics such as POS can be associated with job satisfaction in general. Secondly, psychological empowerment is considered as an important mediating mechanism between perceived organizational support and job satisfaction. Furthermore, proactive personality moderates the relationship between perceived organizational support and psychological empowerment.

Research in organizational behavior draws our attention on a narrow range of job-related attitudes, and POS is one of them. In establishing the proposed associations in the model, the current research represented an attempt to contribute toward literature in number of different manners. The theoretical underpinning of POS is organizational support theory $[29,48]$, which is also based upon social exchange relationship and attribution methods [15, 73]. Organizational support scholars argued that employees tend to monitor their situations and make attributions for generous behaviors of organizations [26]. It is given that individuals tend to personify their respective organizations and consider positive and negative treatments which they receive from organizational 
heads as their perception of being favored or disfavored by organizations as well [65]. Research in the field organizations contended that there is a reciprocal relationship between individuals and organizations. Therefore, it is imperative to consider the organizational support given to the individuals besides focusing on just employee side of this relationship [20].

The tenets, attitudes and aspirations of each employee vary; therefore, motivational elements may be different too. POS can improve individuals' trust and beliefs that the organization identifies their performance and reward them accordingly [61, 72]. As a consequence, individuals will reciprocate [9] the organizational support received by them in several ways and possibly will experience more satisfaction with their job. Therefore, the underlying purpose of the current study is to study the influence of perceived organizational support on job satisfaction.

Secondly, it examines whether psychological empowerment is well incorporated in POS and job satisfaction linkage. Psychological empowerment enables employees to participate in decision making and help in sorting out organizational problems by providing them independence and control [34]. For many years, scholars have examined behavioral consequences of psychological empowerment. Psychological empowerment fosters high-quality relationship by motivating an individual's behavior.

Thirdly, this study corroborates the impact of proactive personality and proposes that it weakens the relationship between POS and psychological empowerment. Proactive personality demonstrates the willingness and the tendency of an employee to go above and beyond their job requirements to exhibit extra-role performance [75]. Henceforth, this research is important to explore and gain insights on the relationship between POS and job satisfaction via the mediating role of psychological empowerment in Asian context. Additionally, to the best of our knowledge, the influence of proactive personality as a moderator has not been examined on the relationship between POS and psychological empowerment (Fig. 1).

\section{Literature review}

\section{Perceived organizational support and job satisfaction}

Armstrong-Stassen [7] explained that individuals' behavior is influenced by their opinion about fundamental processes that constitute their organization and POS is among them. Few scholars have revealed a strong linkage between POS and job satisfaction [23, 30, 33]. In a longitudinal study conducted by Armstrong-Stassen [7], it was observed that managers who enjoy high levels of POS reported elevated levels of job satisfaction as compared to managers who supposed to enjoy lower organizational

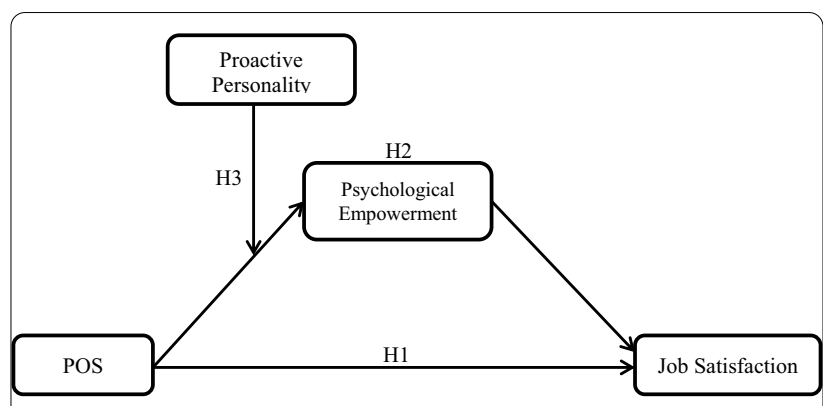

Fig. 1 Theoretical model

support. The potential description of this outcome is that POS can enrich individuals' trust and beliefs that their employer identifies and recompense their struggles to accomplish superior performance [61]. Research suggests that POS starts a social exchange process where individuals feel liable to support the organization in accomplishing its goals which leads to greater rewards. When an employee associates positively with their job and organization, this strengthens the association between them and within the realms of social exchange theory [14]. As a result, individuals reciprocate organizational support through numerous ways and are more satisfied with their jobs. It is given that employees with POS sense an intrinsic compulsion to be socioemotionally devoted to the work and the organization as well. Thus, they are highly loyal and satisfied with their job and organization [36]. On the basis of the above discussion, it is proposed that:

Hypothesis 1 POS is positively related to job satisfaction.

\section{Mediating role of psychological empowerment}

Those individuals who perceive organizational support toward a working situation are likely to experience psychological empowerment [32]. Psychological empowerment is a bundle of circumstances that allows individuals or groups to think that they have a grip over their work [39]. An empirical support has been found about the direct association between POS and job satisfaction [76]. It has been discussed that when individuals experience empowerment, they recognize that their job is important and they can make decisions by their own. They see that their work effects the organizational effectiveness, which in turn advances job performance [18] and satisfaction. It is suggested that prudent organizations give power to its workforce by making them involve in decision making, which makes them believe that their work is meaningful [49]. A recent study has shown that employees' 
psychological empowerment is a source of competitive edge for organizations [56].

It is demonstrated that the employees who receive organizational support show more satisfaction toward their job and have lower turnover rate [49]. A recent study demonstrated that psychological empowerment works as an essential force that intervenes in the association between POS and job satisfaction [8]. Many researches on social exchange [2] and the norms of reciprocity [37] emphasize that employees feel obligated and are ready to assist their coworkers as well as their employers. Similarly, empowered individuals consider themselves as a significant part of the organization, are competent in accomplishing their goals, experience a sense of hold on their job and are involved in activities that affect the organization in a positive way [6]. In the same vein, previous research suggests that when individuals perceive high levels of psychological empowerment, it is highly probable that they feel motivated and dedicated toward their job responsibilities [56].

Furthermore, psychological empowerment works as the key motivator of the individuals' job satisfaction and previous findings have exhibited the positive association between job satisfaction and psychological empowerment [46]. In sum, it is believed that the individuals, who perceive that their organizations recognize their contributions, will feel a greater sense of psychological empowerment, which in return is linked to high job satisfaction $[32,49]$. Thus, it is hypothesized as:

Hypothesis 2 Psychological empowerment mediates the relationship between POS and job satisfaction.

\section{Moderating role of proactive personality}

Specifically, the organizational support theory posits that individuals define their work contributions found on the degree to which they think that their organization is conscious about their welfare. When individuals observe that they are appreciated and employer backed them up, in return they tend to involve in desired actions such as they actively learn, exhibit supportive behavior, show commitment toward their organization and providing beneficial solutions. Individual characteristics such as personalities have an important role in affecting how individuals POS as well as how they act. The proactive, imaginative and tough character of adjustable individuals permits them to obtain these capabilities on their own and take organizational support [25].

By encouraging organizations to be more socially concerned about positive job-family links, workplace circumstances play a proactive role in outlining the vital job and societal consequences [47]. Psychologically empowered workers proactively carry out their work responsibilities [66]. A research revealed that highly proactive individuals are engage more in constructive behaviors such as learning, fabricating a promising work situation, recognizing avenues to grow [70].

In particular, proactive individuals are skillful at developing and maintaining positive give-and-take dealings in the working environment [52]. Therefore, it has been anticipated that proactive individuals with a powerful fundamental force may react to organizational support more favorably than inactive individuals [75]. Psychological empowerment enhances an individual's self-efficacy and the capability to influence one's job environment, promotes proactive behaviors and creative behavior and lets one to perform freely [19].

Organizational support theory advocates that employees' work effort is based upon how much their employing organization is conscious about them and their comfort [61]. The employees consider that they are valued and favored at work and then most probably involved in organization's desired behaviors, including helping others, learning keenly, stay with the organization for longer tenure and offering useful suggestions [61]. Previous research shows that individual differences like proactivity can play as a major force behind affecting how individuals perceive organizational support and behave $[4,75]$.

Help and opinion from interaction with colleagues can deliver precious support to individuals when learning organizational prospects, team rules, grasping work information and adapting social norms of the organization [13]. It is given that highly proactive individuals are unrestricted by situational hindrances and are competent enough to bring changes to enhance their position in organizations [11].

Employees with proactive, resourceful and strong nature acquire and use support from their organization [25]. By modifying office environment to be more socially supported by having strong ties, employment perceptions play a proactive role that determines social outcomes [47].

Moreover, proactive employees also get involved in extra-role organizational behaviors such as designing a constructive working environment and recognizing new avenues [52]. It further helps management in developing such work circumstances where employees consider themselves empowered enough to proactively involve in sustainability behaviors [49]. By integrating the above arguments, it is argued that proactive individuals do not need organization support as they can choose, build and manipulate work conditions in their favor rather than taking organization help. Consequently, proactive personality fades the association between POS and psychological empowerment, as the less organizational support, 
the more proactive employees will be and the more they will be psychologically empowered. Subsequently, it is proposed that

Hypothesis 3 Proactive personality moderates the relationship between POS and psychological empowerment, such that this relationship is stronger when proactive personality is low rather than high.

\section{Research methods}

\section{Sample and procedure}

Data were collected from practitioners belonging to various job functions (e.g., administration, corporate services, engineering, construction works, information and communication technology, education, public relation and media) from both services and manufacturing organizations located in the Punjab province of Pakistan. For sample selection, purposive sampling was utilized in order to get responses from the information-rich cases by proper utilization of available means [31]. Moreover, in order to minimize the effect of common method bias, data were collected from participants in two waves (one-month gap between both the time waves) [58] through self-administered questionnaires prepared in English language as English is considered as the medium of communication across these organizations. The participants were asked to fill out the questionnaire for perceived organizational support and proactive personality at Time 1 (T1). One month later, data were collected at Time 2 (T2), where participants were asked to fill up the questionnaire for psychological empowerment and job satisfaction. The data were collected from the target respondents in a natural setting without any interference from the researcher.

By keeping in mind the possibilities of missing data and nonrespondents, our team approached 1200 full-time employees from manufacturing and services organizations. In response, we received back 1186 questionnaires, from which 936 were completed and valid; besides that, those with incomplete and missing data were removed from the analysis.

In the sample of 936 respondents, the majority were from services industries $(821,87.7 \%)$ and the remaining respondents belong to manufacturing industries (103, 11.0\%); 651 participants were male, while 285 were females (30.4\%). The average age of the respondents was 29.68 years $(\mathrm{SD}=7.24)$ with average education level of 15.67 years $(\mathrm{SD}=1.51)$. The average length of time spent with current organization was 5.06 years. In addition, the majority of the respondents were singles (501, 53.5\%).

\section{Measures}

For measuring the study variables, well recognized and most extensively used scales were adopted from the previous studies.

Perceived organizational support Perceived organizational support was measured using eight-item scale developed by Eisenberger et al. [28]. Employees were requested to assess the degree of their perceived organizational support by using a five-point Likert scale ranging from $1=$ strongly disagree to $5=$ strongly agree. One of sample items is "My organization strongly considers my goals and values," and its internal consistency was 0.88 .

Job satisfaction We measured overall job satisfaction by a single-item scale developed by Scarpello and Campbell [64] that assessed participant's satisfaction with their current job on seven-point Likert scale ranging from $1=$ not at all to $7=$ very much. The item for overall satisfaction is "Do you mostly enjoy your work in this organization."

Psychological empowerment To measure psychological empowerment of employees, 12-item scale was used by Spreitzer [66]. The sample item is "The work I do is very important to me," and it is measured on a fivepoint Likert scale ranging from $1=$ strongly disagree to $5=$ strongly agree. The internal consistency for this scale was 0.85 .

Proactive personality Proactive personality was measured using 5-item scale developed by Janssen et al. [43]. Employees were asked for their proactive personality using a six-point Likert scale ranging from $1=$ very strongly disagree to $5=$ very strongly agree. The sample item is "wherever I have been, I have been a powerful force for constructive change," and its internal consistency was 0.76 .

Control variables We controlled for several potentially relevant variables including thriving at work (joint connection of learning and vitality), age $(1=$ less than 20 till $6=60$ and above), gender ( $1=$ male, $2=$ female), marital status $(1=$ single, $2=$ married, $3=$ widow, $4=$ divorced $)$, education level $(1=$ graduate, $2=$ postgraduate, $3=$ doctorate) and tenure ( $1=0-5$ till $5=21$ and above). Previous research indicated that particularly age, marital status and years of experience significantly correlate with job satisfaction $[45,54]$. It is purported that gender differences should be given due consideration in the attitude-performance equation in the domain of organizational studies, as Crossman and Abou-Zaki [24] also suggested that job satisfaction level among males is generally more than females. The educational level is also critical as the employees with different educational levels exhibit diverse attitudes and satisfaction level at work [3]. Employee tenure is controlled due its impact on job satisfaction and POS. Owens et al. [57] noted that works at their beginning of job or career with particular 
organization are more excited and energetic about their work.

\section{Data analysis}

Frequency analysis was used to determine the demographic characteristics of the sample, descriptive statistics were used for control and study variables, reliabilities of scales were computed and correlation matrix was computed as well. Confirmatory factor analysis was conducted to test the construct validity of the measurement model, while regression analysis was used to test the moderated mediation hypotheses and validity of the model.

\section{Results}

Table 1 presents the mean, SDs, correlation values and Cronbach's alphas. Correlation coefficients are in the anticipated directions and provide preliminary support for our study hypotheses. For the control variables, it is examined that the relationship between gender and marital status is negatively significant $(r=-0.16, p<0.01)$; age and gender $(r=-0.21, p<0.01)$; and tenure and gender $(r=0.15, p<0.01)$, and the relationship between tenure and marital status is positively significant $(r=0.43$, $p<0.01)$; that between age and marital status $(r=0.59$, $p<0.01)$ is positively correlated.

POS has a positive and significant relationship with psychological empowerment $(r=0.46, p<0.01)$; proactive personality is negatively significant with gender $(r=-0.07, p<0.05)$; proactive personality is positively significant with POS $(r=0.23, p<0.01)$; proactive personality and psychological empowerment $(r=0.26, p<0.01)$. Furthermore, job satisfaction is positively significant with other study variables, job satisfaction with POS $(r=0.34$, $p<0.01)$; job satisfaction with psychological empowerment $(r=0.38, p<0.01)$; and job satisfaction with proactive personality $(r=0.20, p<0.01)$.

\section{Confirmatory factor analysis}

Confirmatory factor analysis (CFA) was conducted in order to determine instrument validity by using Fornell and Larcker [35] validity assessment criterion. At first, we examined full three-factor measurement model in which the items were permitted to associate substantially with their respective factors. Then, following up by other combination of our items related to our three study variables in AMOS 24 was examined. Results of our hypothesized full measurement model (perceived organizational support, proactive personality and psychological empowerment) represented a reasonably good fit, which can be seen in Table 2, as Chi-square $=1798.21$, TLI $=0.98$, $\mathrm{IFI}=0.99, \quad \mathrm{CFI}=0.99, \quad \mathrm{AGFI}=0.98, \quad \mathrm{RMSEA}=0.05$, $\mathrm{SRMR}=0.05$. All of these indices fall into the acceptable limits.

The full measurement model was also compared with other different factor models in order to find out the best fit model for our data. Further, results showed that the full measurement model is the best fit model for our dataset and that other models did not provide an acceptable model fit at $\mathrm{p}<0.05$. The findings suggest that perceived organizational support, proactive personality and psychological empowerment are distinctive constructs.

\section{Construct reliability and validity}

The composite reliabilities (CR) of all of our study constructs lie within the range of 0.77 to 0.89 , and AVE values are greater than 0.53 ; hence, the convergent validity is found to be satisfied. Besides, the criteria of discriminant validity set out by Fornell and Larcker [35] are also fulfilled, as AVE values of every construct of the study are found to be greater than their corresponding squared correlation.

\section{Test for moderated mediation}

In order to compute moderated mediation tests, hypothesized theoretical model was evaluated, in which the

Table 1 Mean, SDs and correlations

\begin{tabular}{|c|c|c|c|c|c|c|c|c|c|c|}
\hline Variables & Mean & SD & 1 & 2 & 3 & 4 & 5 & 6 & 7 & 8 \\
\hline 1. Gender & - & - & - & & & & & & & \\
\hline 2. Marital status & - & - & $0.16^{* *}$ & - & & & & & & \\
\hline 3. Age & 29.68 & 7.23 & $0.21^{* *}$ & $0.59^{* *}$ & & & & & & \\
\hline 4. Qualification & 15.67 & 1.50 & $0.06^{*}$ & $0.08^{*}$ & $0.12^{*}$ & & & & & \\
\hline 5. Tenure & 5.06 & 5.17 & $0.15^{* *}$ & $0.43^{* *}$ & $0.74^{*}$ & -0.05 & & & & \\
\hline 6. POS & 3.69 & 0.67 & -0.02 & -0.03 & 0.01 & -0.06 & -0.05 & $(0.88)$ & & \\
\hline 7. Psychological Empowerment & 3.96 & 0.56 & -0.06 & -0.05 & 0.01 & -0.02 & -0.03 & $0.46^{* *}$ & $(0.85)$ & \\
\hline 8. Proactive Personality & 4.41 & 0.72 & $0.07^{*}$ & -0.03 & -0.01 & -0.00 & -0.00 & $0.23^{* *}$ & $0.26^{* *}$ & $(0.76)$ \\
\hline 9. Job Satisfaction & 5.24 & 1.30 & 0.04 & -0.03 & 0.02 & -0.02 & -0.01 & $0.34^{* *}$ & $0.38^{* *}$ & $0.20^{* *}$ \\
\hline
\end{tabular}

${ }^{*} p<0.05 ;{ }^{* *} p<0.01$ 
Table 2 Fit statistics from measurement model comparison

\begin{tabular}{|c|c|c|c|c|c|c|c|c|c|c|c|c|}
\hline Models & $x^{2}$ & df & $x^{2} / d f$ & TLI & IFI & AGFI & $\mathrm{CFI}$ & SRMR & RMSEA & AIC & $\Delta \mathrm{x}^{2}$ & $\Delta \mathrm{df}$ \\
\hline $\begin{array}{l}\text { Full measure- } \\
\text { ment model }\end{array}$ & 1798.21 & 529 & 3.49 & 0.98 & 0.99 & 0.98 & 0.99 & 0.05 & 0.05 & 2000.21 & & \\
\hline Model A & 1281.09 & 509 & 2.52 & 0.93 & 0.94 & 0.91 & 0.94 & 0.04 & 0.04 & 1523.09 & 517.21 & 28 \\
\hline Model B & 4255.26 & 557 & 7.64 & 0.68 & 0.70 & 0.72 & 0.71 & 0.06 & 0.08 & 4401.26 & 2974.17 & 20 \\
\hline Model C & 4385.14 & 557 & 7.87 & 0.67 & 0.69 & 0.72 & 0.69 & 0.06 & 0.08 & 4531.14 & 129.88 & 0 \\
\hline Model D & 6168.18 & 560 & 11.05 & 0.52 & 0.55 & 0.62 & 0.55 & 0.08 & 0.10 & 6327.18 & 629.54 & 1 \\
\hline
\end{tabular}

All models are compared with full measurement model, i.e., five-factor model which includes (perceived organizational support, proactive personality, psychological empowerment, and thriving at work is divided into learning and vitality), where job satisfaction is excluded as it is a global measure. A. Three-factor model, where perceived organizational support and proactive personality are taken as a combined factor and psychological empowerment as a separate factor. B. Two-factor model, where psychological empowerment and perceived organizational support are combined into one factor and proactive personality as a separate factor. C. One-factor model, where psychological empowerment and proactive personality are combined into one factor and perceived organizational support as a separate factor. D. Onefactor model in which all four constructs are combined into one factor

$X^{2}$ Chi-square, $d f$ degrees of freedom, TLITucker-Lewis index, IFI incremental fit index, CFI comparative fit index, AGFI adjusted goodness-of-fit index, RMSEA rootmean-square error of approximation, SRMR standardized root-mean-square residual

$n=936 ;{ }^{* *} p<0.05$

influence of POS on job satisfaction was seen via psychological empowerment that was conditional on proactive personality. Here, moderated mediation technique was used and was run in one step by using SPSS Process Macro Model 7 [60] with 95\% confidence interval based on 5000 bootstrap samples. Further, the coefficients of the model were estimated, whereby proactive personality interacts with perceived organizational support to influence psychological empowerment of employees, which in return impacts job satisfaction. It is given that results of moderated mediation analysis are presented in Table 3.

Firstly, the results support our assumptions for the hypothesized moderated mediation model. Secondly, when psychological empowerment is taken as outcome variable, Table 3 depicts the $R^{2}$ value which tells us that

Table 3 Regression results for moderated mediation-psychological empowerment as mediator

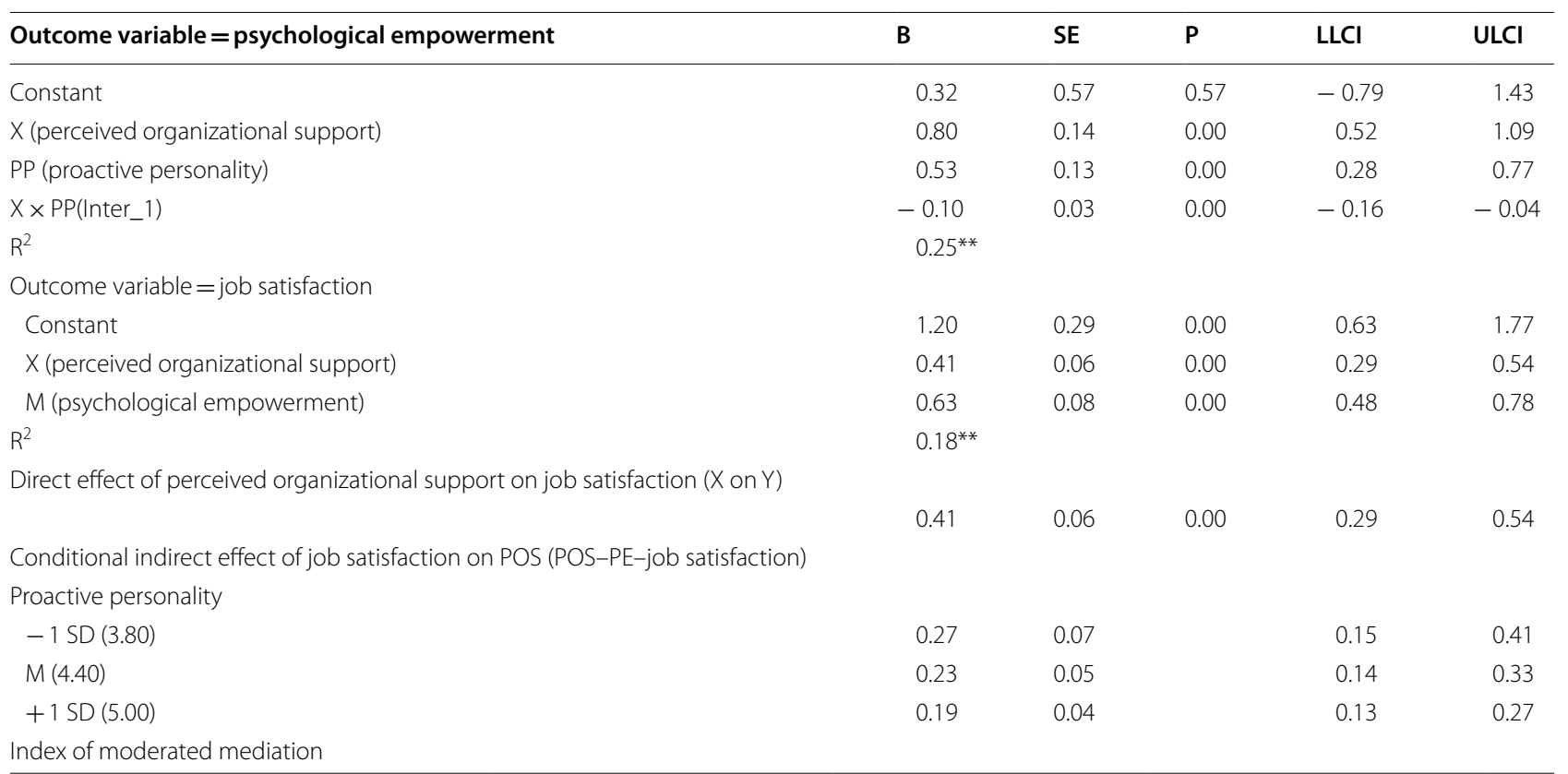

\begin{tabular}{lllll}
\hline \multicolumn{4}{c}{ Index } & \\
\hline Proactive personality & -0.07 & 0.04 & -0.16
\end{tabular}

$N=936 ; \beta=$ unstandardized regression coefficient; $\mathrm{SE}=$ standard error; $\mathrm{LL}=$ lower limit; $\mathrm{Cl}=$ confidence interval; $\mathrm{UL}=$ upper limit 
psychological empowerment explains $25 \%$ of the variance in proactive personality in individuals and moderation is shown up by a significant interaction effect $(\beta=-0.10)$ that explains the relationship is negative and significant and also that as psychological empowerment increases, proactive personality decreases in the individuals. Given that $p$ value $p<0.01$, i.e., $\mathrm{p}=0.00$, shows that psychological empowerment is a highly significant predictor of proactive personality, then the boundaries of the zone of significance are between -0.16 and -0.04 , which defines that psychological empowerment is significant to proactive personality.

The model further illustrates the positive direct effect of job satisfaction on POS as $\beta=0.41, \mathrm{SE}=0.06, p<0.01$. The conditional indirect effect of job satisfaction on POS through psychological empowerment was probed at three different values of proactive personality: one SD below the mean (i.e., 3.80), on the average (4.40) and one $\mathrm{SD}$ above the mean (5.00). The indirect effect was significantly different from zero among low $(\beta=0.27,95 \%$ $\mathrm{CI}=0.15$ to 0.41$)$; average $(\beta=0.23,95 \% \mathrm{CI}=0.14$ to $0.33)$; and high ( $\beta=0.19,95 \% \mathrm{CI}=0.13$ to 0.27$)$ for proactive personality individuals. In addition, the index of moderated mediation reveals that the conditional indirect effect of psychological empowerment in the analysis of job satisfaction regressed on POS $\times \mathrm{PP}$ is significant as indirect effect was -0.07 and $95 \%$ bootstrapping CI of this relationship did not include zero ( $\mathrm{LLCI}=-0.16$ to $\mathrm{ULCI}=-0.04)$. Moreover, results demonstrated that the positive impact of POS on job satisfaction through psychological empowerment increases as proactive personality decreases in the employees. These findings are in the anticipated direction (Fig. 2).

Conditional indirect effect of $\mathrm{X}$ on $\mathrm{Y}$ can be estimated through the following regression equation:

$$
\mathrm{M}=(0.80-0.10 \mathrm{~W}) 0.63
$$

While Direct effect of $\mathrm{X}$ on $\mathrm{Y}=0.41$

where $\mathrm{X}$ is the perceived organizational support (POS), $\mathrm{Y}$ is the job satisfaction, $\mathrm{W}$ is the proactive personality and $\mathrm{M}$ is the psychological empowerment.

This moderated mediation graph shows the indirect effects of POS on job satisfaction through psychological empowerment at higher (1 SD higher) and lower (1 SD lower) levels of proactive personality. These findings provided support for our Hypothesis 3 (Fig. 3).

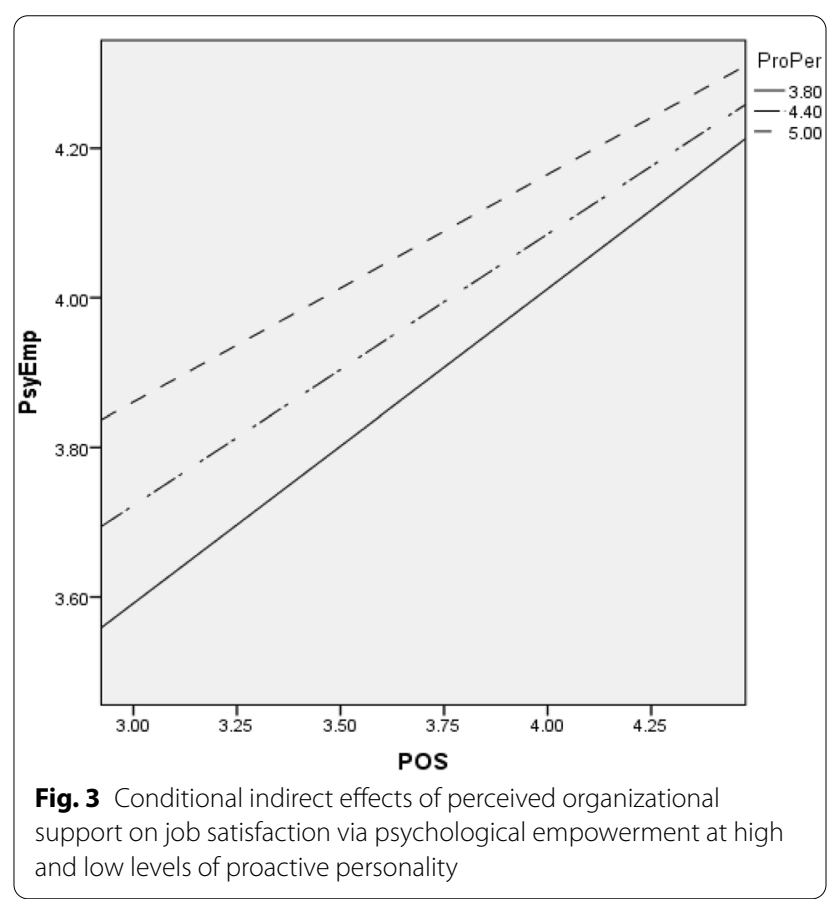

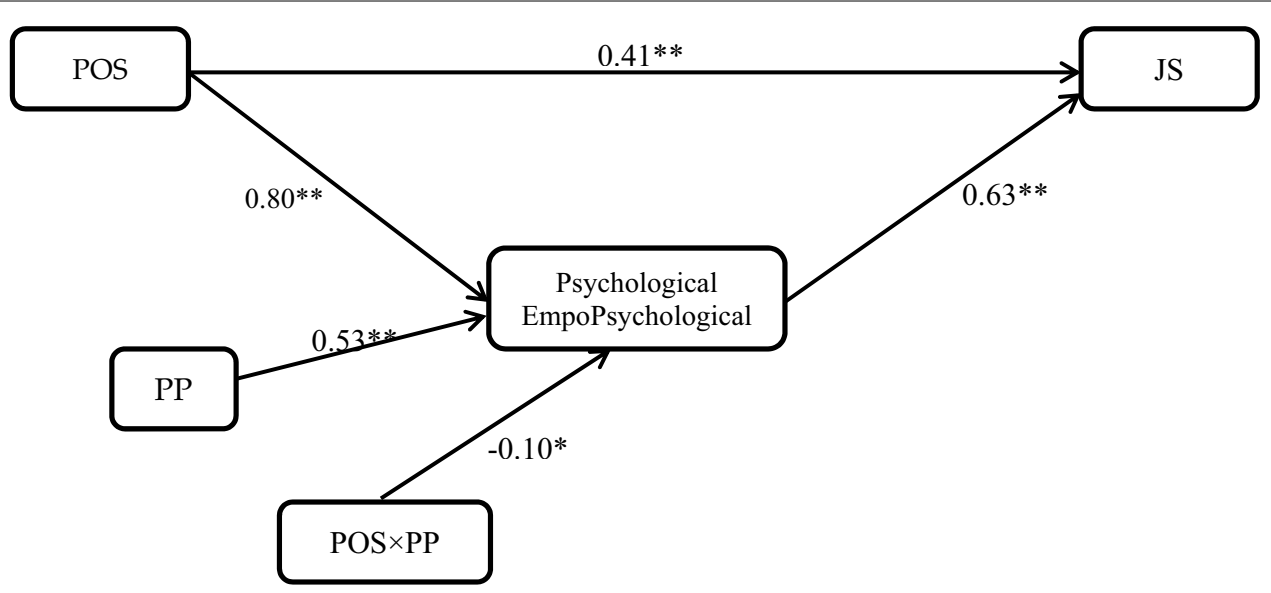

Fig. 2 Moderated mediation model 


\section{Discussion}

The main focus of the study was to examine the influence of POS on job satisfaction and to provide an insight into the complex mechanism of moderated mediation. Psychological empowerment functions as a mediator between POS and job satisfaction, and proactive personality showed an indirect effect on the association between POS and psychological empowerment. The current study findings provide support for the hypothesized model, which are as follows:

Being consistent with Hypothesis 1, the results demonstrated the positive association between POS and job satisfaction. Our results supported the findings of Alcover et al. [5]. The results show that the positive role of POS on job satisfaction is persistent in case, when individuals perceive that their organization assesses their participation to the organizational goals favorably and are conscious about their welfare. Resultantly, they experience job satisfaction.

Favoring Hypothesis 3, the present study findings provide support for moderated linkage, corroborating the extent of the negative impact of proactive individuals whereby it weakens the relationship between POS and psychological empowerment. Proactive individuals help managers to progress in such environmental situations where individuals feel empowered to proactively involve in sustainable behaviors. Subsequently, the organizational support is not required by the employees as they create and impact job situations in their favor by themselves, rather taking organization's help. Thus, proactive personality has moderated the connection between POS and $\mathrm{PE}$ in a manner that the said association is robust when PP is less rather than high.

\section{Theoretical contributions}

This research offers imperative contribution in the literature by associating and encompassing the previous outcomes in multiple manners. Organizational behavior centers attention on a very few work-related attitudes, and POS and job satisfaction are two of them. The individuals and organizations are involved in a give-and-take relationship when research on the organization is considered. In establishing the proposed associations in the moderated mediation model, the current research will make several contributions.

First, we contributed to the research on POS by suggesting and confirming the positive association between POS (i.e., a characteristic where working behavior of individuals and attitudes are influenced by an individual's perception of main phenomenon that describes their organization) and job satisfaction (among thorough researched constructs in management research/ organizational behavior). Using social exchange theory, we contend that psychological empowerment can exert mediating effects linking POS and job satisfaction.

Psychological empowerment support employees in their decision making and problems solving thus providing independence and control. These results are of great significance as they give understanding into how employees or individuals may affect other individuals' psychological insights, learning and vitality at work, which in turn influence their behavior. Although past researches had not provided ample evidences for the linkage between psychological empowerment and proactive personality, we advanced the literature of proactive personality as a moderator.

\section{Practical implications}

Our findings contribute to overcoming the problems of employees in manufacturing and service sectors as the findings also provide practical implication for managers and practitioners. This research was able to manage a strong understanding of POS, job satisfaction, psychological empowerment and proactive personality.

Manufacturing and services managers should focus on creating and enhancing employee belongings stimulus to avoid the employee turnover. Organizations can strive to provide advocates that are customized to address individual employee's necessities. The individuals remain in the firm if he/she realizes a high support level (in terms of social and emotional support) [42]. If an employee receives the support, he/she will perceive it as favorable characteristic of a firm. For estimating the employee's performance in comparison with their jobs, job satisfaction is a vital feature that benefits the organization [42]. Managers must understand that every employee has different necessities and expectations which need to be fulfilled. Thus, they should provide support to their employees, including motivated working conditions, flexible working hours and fairly paid salary which resultantly can enhance job satisfaction.

The management should uphold and strengthen the prevailing levels of psychological empowerment and should make strategies to improve it as it can move toward work efficiency and satisfaction without financial expense. Management should empower employees through involvement, support system, information sharing, rewards, tasks handling and by providing chances to take decisions.

Proactive individuals are uneffected by situational factors and probably generate variations to mend their position in the organizational hierarchy [11]. The proactive and adaptable employees acquire and use support from their organization to make situation in their favour [25]. Organizations change their policies to be more socially 
supported by providing positive work-family association. Lastly, this study will offer assistance to managers who are interested in inspiring individual's satisfaction with his job by enhancing psychological empowerment, job satisfaction and POS within their organizations.

\section{Limitations and future directions}

Firstly, by investigating the variable associations, the research revealed an important relationship between $\mathrm{PE}$ and POS but still said the association needs more comprehensive explanation. A supposition regarding their association stated at the time when employees are empowered by the organization the organizational support is realized. Forthcoming studies should further explore the association between these variables.

The second potential limitation is that this research studied different manufacturing and services industries of Lahore, Pakistan; however, individuals from other cultures and identities may reveal diverse psychosomatic insights. Accordingly, comparisons can be observed by taking into account cultural differences.

The third limitation is that causality between the study variables cannot be drawn because of cross-sectional research design. So, it is suggested that future studies should conduct experimental/longitudinal strategies to discover the possible reciprocal relationships.

Our unit of analysis was individual based. Comparison was performed between the variables like individual's perceived organizational support effect on individual's job satisfaction, etc. So it is recommended that future research must include unit of analysis in the form of groups or departmental levels [67] as well as teams.

This research work observed the direct association between psychological empowerment and job satisfaction. In the future, it should be seen that psychological empowerment could have an indirect relationship with job satisfaction.

We controlled employee age, gender, marital status, educational level, job type and work experience in order to avoid confounding effects on examined relationships. As in future studies, these could be added as study variables with different demographic characteristics possessing different constituents or consequences of POS, job satisfaction, psychological empowerment and proactive personality.

Lastly, in the future, it is suggested that proactive personality could also function as a moderator of the other associations of the current study model, i.e., between psychological empowerment and job satisfaction. It is given that having the critical role of proactive behavior in organizations, effective measures should be taken to inspire employee proactivity. Examining these mechanisms would probably offer counselors, scholars and psychologists the substitutes for interventions in the future.

\section{Conclusion}

This research work makes vital additions in the fields of organizational behavior and applied psychology. The integrated study model revealed the relationship between POS and job satisfaction through the mediating role of psychological empowerment and the moderating impact of proactive personality. The practical findings provide support for organizational support theory and social exchange theory, which entails the groundings for the linkage between these associations. The study examines the intervening effect of psychological empowerment on the relationship between POS and job satisfaction. In addition, the study provides a contribution to the proactive personality by drawing attention to its indirect effect mechanisms that influence the relationship between POS and psychological empowerment. This research highlighted the importance of the fact that the organizations are not compelled to just focus on the empowerment of the employees but should also care for their well-being. The more they channelize the energies of their employees, the more they are satisfied with their job.

\section{Acknowledgements \\ None.}

Authors' contributions

ATM was involved in conceptualization. ATM, THB and GA supported data curation. ATM was involved in formal analysis. ATM and FA were involved in investigation. THB and SA contributed to methodology. GA contributed to project administration. ATM and FA contributed resources. GA was involved in supervision. THB and GA were involved in validation. GA was involved in visualization. ATM contributed to writing — original draft. THB, GA and SA contributed to writing - review and editing. All authors read and approved the final manuscript.

\section{Funding}

The authors acknowledge that they received no external funding in support of this research.

\section{Availability of data and materials}

The datasets generated during and/or analyzed during the current study are available from the corresponding author on reasonable request.

\section{Competing interests}

The authors declare that they have no competing interests.

\section{Author details}

${ }^{1}$ School of Business Administration, National College of Business Administration and Economics, Lahore, Pakistan. ${ }^{2}$ Lahore College for Women University, Lahore, Pakistan. ${ }^{3}$ Institute of Business and Management, University of Engineering and Technology, Lahore, Pakistan.

Received: 10 October 2019 Accepted: 12 March 2020

Published: 25 June 2020 


\section{References}

1. Abid G, Zahra l, Ahmed A (2015) Mediated mechanism of thriving at work between perceived organization support, innovative work behavior and turnover. Pak J Commer Soc Sci 9:982-998

2. Arshadi N (2011) The relationships of perceived organizational support (POS) with organizational commitment, in-role performance, and turnover intention: mediating role of felt obligation. Procedia Soc Behav Sci 30:1103-1108

3. Atwater L, Carmeli A (2009) Leader-member exchange, feelings of energy and involvement in creative work. Leadersh Q 20:264-275

4. Akgunduz Y, Alkan C, Gok OA (2018) Perceived organizational support, employee creativity and proactive personality: the mediating effect of meaning of work. J Hosp Tour Manag 34:105-114

5. Alcover CM, Chambel MJ, Fernandez JJ, Rodriquez F (2018) Perceived organizational support-burnout-satisfaction relationship in workers with disabilities: the moderation of family support. Scand J Psychol 59:1-11

6. Amundsen S, Martinsen OL (2015) Linking empowering leadership to job satisfaction, work effort, and creativity: the role of self-leadership and psychological empowerment. J Leadersh Organ Stud 22:304-323

7. Armstrong-Stassen M (1998) Downsizing the federal government: a longitudinal study of managers' reactions. Can J Adm Sci 15:310-321

8. Aydogmus C, Camgoz SM, Ergeneli A, Ekmekci OT (2017) Perceptions of transformational leadership and job satisfaction: the roles of personality traits and psychological empowerment. J Manag Organ 23:1-27

9. Baker WE, Bulkley N (2014) Paying it forward vs. rewarding reputation: mechanisms of generalized reciprocity. Organ Sci 25:1493-1510

10. Bateman TS, Crant JM (1993) The proactive component of organizational behavior: a measure and correlates. J Organ Behav 14:103-118

11. Bateman TS, Crant JM (1999) Proactive behavior: meanings, impact, and recommendations. Bus Horiz 42:63-70

12. Berger PJ, Neuhaus RJ (1977) To empower the people: the role of mediating structures in public policy. American Enterprise Institute for Public Policy Research, Washington

13. Bergeron DM, Schroeder TD, Martinez HA (2014) Proactive personality at work: seeing more to do and doing more? J Bus Psychol 29:71-86

14. Biswas S, Bhatnagar J (2013) Mediator analysis of employee: role of perceived organizational support, $\mathrm{p}$-o fit, organizational commitment and job satisfaction. Research 38:27-40

15. Blau P (1964) Exchange and power in social life. Wiley, New York

16. Carless SA (2004) Does psychological empowerment mediate the relationship between psychological climate and job satisfaction? J Bus Psychol 18:405-425

17. Chang LC, Liu CH (2008) Employee empowerment, innovative behavior and job productivity of public health nurses: a cross-sectional questionnaire survey. Int J Nurs Stud 45:1442-1448

18. Chiang CF, Hsieh TS (2012) The impacts of perceived organizational support and psychological empowerment on job performance: the mediating effects of organizational citizenship behavior. Int J Hosp Manag 31:180-190

19. Chung YW (2018) Workplace ostracism and workplace behaviors: a moderated mediation model of perceived stress and psychological empowerment. Anxiety Stress Coping 31:304-317

20. Conway N, Coyle-Shapiro JA (2012) The reciprocal relationship between psychological contract fulfilment and employee performance and the moderating role of perceived organizational support and tenure. J Occup Organ Psychol 85:277-299

21. Coyle-Shapiro JA, Conway N (2005) Exchange relationships: examining psychological contracts and perceived organizational support. J Appl Psychol 90:774

22. Crant JM (2000) Proactive behavior in organizations. J Manag 26:435-462

23. Cropanzano R, Howes JC, Grandey AA, Toth P (1997) The relationship of organizational politics and support to work behaviors, attitudes, and stress. J Organ Behav 18:159-180

24. Crossman A, Abou-Zaki B (2003) Job satisfaction and employee performance of Lebanese banking staff. J Manag Psychol 18:368-376

25. Cullen KL, Edwards BD, Casper WC, Gue KR (2014) Employees'adaptability and perceptions of change-related uncertainty: implications for perceived organizational support, job satisfaction, and performance. J Bus Psychol 29:269-280

26. Eisenberger R, Huntington R, Hutchison S, Sowa D (1986) Perceived organizational support. J Appl Psychol 71:500-507
27. Eisenberger R, Lynch P, Aselage J, Rohdieck S (2004) Who takes the most revenge? Individual differences in negative reciprocity norm endorsement. Pers Soc Psychol Bull 30:789-799

28. Eisenberger R, Cummings J, Armeli S, Lynch P (1997) Perceived organizational support, discretionary treatment, and job satisfaction. J Appl Psychol 82:812-820

29. Eisenberger R, Armeli S, Rexwinkel B, Lynch PD, Rhoades L (2001) Reciprocation of perceived organizational support. J Appl Psychol 86:42-51

30. Erdogan B, Enders J (2007) Support from the top: supervisors' perceived organizational support as a moderator of leader-member exchange to satisfaction and performance relationships. J Appl Psychol 92:321-330

31. Etikan I, Musa SA, Alkassim RS (2016) Comparison of convenience sampling and purposive sampling. Am J Theor Appl Stat 5:1-4

32. Ertürk A (2010) Exploring predictors of organizational identification: moderating role of trust on the associations between empowerment, organizational support, and identification. Eur J Work Organ Psychol 19:409-441

33. Filipova AA (2010) Relationships among ethical climates, perceived organizational support, and intent-to-leave for licensed nurses in skilled nursing facilities. J Appl Gerontol 301:1-23

34. Fong KH, Snape E (2015) Empowering leadership, psychological empowerment and employee outcomes: testing a multi-level mediating model. Br J Manag 26:126-138

35. Fornell C, Larcker DF (1981) Evaluating structural equation models with unobservable variables and measurement error. J Mark Res 18:39-50

36. Gillet N, Colombat P, Michinov E, Pronost AM, Fouquereau E (2013) Procedural justice, supervisor autonomy support, work satisfaction, organizational identification and job performance: the mediating role of need satisfaction and perceived organizational support. J Adv Nurs 69:2560-2571

37. Gouldner A (1960) The norm of reciprocity:a preliminary statement. J Am Sociol Rev 25:161-178

38. Guan Y, Dai X, Gong Q, Deng Y, Hou Y, Dong Z et al (2017) Understanding the trait basis of career adaptability: a two-wave mediation analysis among Chinese university students. J Vocat Behav 101:32-42

39. Hechanova MRM, Alampay RBA, Franco EP (2006) Psychological empowerment, job satisfaction and performance among Filipino service workers Asian. J Soc Psychol 9:72-78

40. Hu C, Wang S, Yang CC, Wu TY (2014) When mentors feel supported: relationships with mentoring functions and protégés' perceived organizational support. J Organ Behav 35:22-37

41. Huang J (2017) The relationship between employee psychological empowerment and proactive behavior: self-efficacy as mediator. Soc Behav Personal 45:1157-1166

42. Hui CS, Yee CS, Yen LS, Chie LA, Yi LC (2017) The impact of perceived organizational support, job satisfaction, leader-member exchange (LMX) and work-life balance on employee's turnover intention in manufacturing industry, Malaysia. Final year project, UTAR 1-194. http://eprints.utar.edu. my/2646/1/Final_Year_Project_(Group_9).pdf

43. Janssen AB, Schultze $\bar{M}$, Grotsch A (2017) Following the ants: development of short scales for proactive personality and supervisor support by ant colony optimization. Eur J Psychol Assess 33:409-421

44. Jiang Z (2017) Proactive personality and career adaptability: the role of thriving at work. J Vocat Behav 98:85-97

45. Kalliath P, Kalliath T, Chan XC, Chan C (2018) Linking work-family enrichment to job satisfaction through job well-being and family support: a moderated mediation analysis of social workers across India. Br J Soc Work 18:1-22

46. Khany R, Tazik K (2016) On the relationship between psychological empowerment, trust, and Iranian EFL teachers' job satisfaction: the case of secondary school teachers. J Career Assess 24:112-129

47. Kossek EE, Pichler S, Bodner T, Hammer LB (2011) Workplace social support and work-family conflict: a meta-analysis clarifying the influence of general and work-family-specific supervisor and organizational support. Pers Psychol 64:289-313

48. Kurtessis JN, Eisenberger R, Ford MT, Buffardi LC, Stewart KA, Adis CS (2017) Perceived organizational support: a meta-analytic evaluation of organizational support theory. J Manag 43:1854-1884

49. Lamm E, Tosti-Kharas J, King CE (2015) Empowering employee sustainability:perceived organizational support toward the environment. J Bus Ethics 128:207-220 
50. Laschinger HKS, Finegan J (2005) Using empowerment to build trust and respect in the workplace: a strategy for addressing the nursing shortage. Nurs Econ 23:6-13

51. Lavelle JJ, Rupp DE, Brockner J (2007) Taking a multifoci approach to the study of justice, social exchange and citizenship behavior: the target similarity model? J Manag 33:841-866

52. Li N, Liang J, Crant JM (2010) The role of proactive personality in job satisfaction and organizational citizenship behavior: a relational perspective. J Appl Psychol 95:395-404

53. McArdle S, Waters L, Briscoe JP, Hall DT (2007) Employability during unemployment: adaptability, career identity and human and social capital. J Vocat Behav 71:247-264

54. van der Meer L, Nieboer AP, Finkenflugel H, Cramm LM (2017) The importance of person-centred care and co-creation of care for the wellbeing and job satisfaction of professionals working with people with intellectual disabilities. Scand J Caring Sci 32:76-81

55. Molix L, Bettencourt BA (2010) Predicting well-being among ethnic minorities: psychological empowerment and group identity. J Appl Soc Psychol 40:513-533

56. Olçer F, Florescu MS (2015) Mediating effect of job satisfaction in the relationship between psychological empowerment and job performance. Bus Excell Manag 5:5-32

57. Owens BP, Baker WE, Sumpter DM, Cameron KS (2016) Relational energy at work: implications for job engagement and job performance. J Appl Psychol 101:35-49

58. Podsakoff PM, MacKenzie SB, Lee J-Y, Podsakoff NP (2003) Common method biases in behavioral research: a critical review of the literature and recommended remedies. J Appl Psychol 88:879-903

59. Porath C, Spreitzer G, Gibson C, Garnett FG (2012) Thriving at work: toward its measurement, construct validation, and theoretical refinement. J Organ Behav 33:250-275

60. Preacher KJ, Hayes AF (2008) Asymptotic and resampling strategies for assessing and comparing indirect effects in multiple mediator models. Behav Res Methods 40:879-891

61. Rhoades L, Eisenberger R (2002) Perceived organizational support: a review of the literature. J Appl Psychol 87:698-714

62. Robbins SP, Judge TA (2013) Group property: norms. In: Robbins SP, Judge TA (eds) Organizational behavior, 15th edn. Pearson, London, p 314

63. Savery LK, Luks JA (2001) The relationship between empowerment, job satisfaction and reported stress levels: some Australian evidence. Leadersh Organ Dev J 22:97-104

64. Scarpello V, Campbell JP (1983) Job satisfaction: are all the parts there? Pers Psychol 36:577-600

65. Shanock LR, Eisenberger R (2006) When supervisors feel supported: relationships with subordinates' perceived supervisor support, perceived organizational support, and performance. J Appl Psychol 91:689-695
66. Spreitzer GM (1995) Psychological empowerment in the workplace: dimensions, measurement, and validation. Acad Manag J 38:1442-1465

67. Spreitzer G, Sutcliffe K, Dutton J, Sonenshein S, Grant AM (2005) A socially embedded model of thriving at work. Organ Sci 16:537-549

68. Tolentino LR, Garcia PRJ, Lu VN, Restubog SLD, Bordia P, Plewa C (2014) Career adaptation: the relation of adaptability to goal orientation, proactive personality, and career optimism. J Vocat Behav 84:39-48

69. Uy MA, Chan KY, Sam YL, Ho MH, Chernyshenko OS (2015) Proactivity, adaptability and boundaryless career attitudes: the mediating role of entrepreneurial alertness. J Vocat Behav 86:115-123

70. Wang Z, Zhang J, Thomas CL, Yu J, Spitzmueller C (2017) Explaining benefits of employee proactive personality: the role of engagement, team proactivity composition and perceived organizational support. J Vocat Behav 101:90-103

71. Walumbwa FO, Muchiri MK, Misati E, Wu C, Meiliani M (2017) Inspired to perform: a multilevel investigation of antecedents and consequences of thriving at work. J Organ Behav 39:249-261

72. Wayne SJ, Shore LM, Bommer WH, Tetrick LE (2002) The role of fair treatment and rewards in perceptions of organizational support and leadermember exchange. J Appl Psychol 87:590

73. Wayne SJ, Shore LM, Liden RC (1997) Perceived organizational support and leader-member exchange: a social exchange perspective. Acad Manag J 40:82-111

74. Yih W, Lawrence SH (2011) The impacts of perceived organizational support, job satisfaction, and organizational commitment on job performance in hotel industry. Taipei, Taiwan

75. Xiong L, King C (2018) Too much of a good thing? Examining how proactive personality affects employee brand performance under formal and informal organizational support. Int J Hosp Manag 68:12-22

76. Yen RHJ, Lin YL, Tai SH (2004) The impacts of service climate on serviceoriented citizenship behavior, the mediating roles of psychological empowerment and role definition. Manag Rev 23:25-48

77. Yu C, Frenkel SJ (2013) Explaining task performance and creativity from perceived organizational support theory: which mechanisms are more important? J Organ Behav 34:1165-1181

78. Zhang J, Zheng W (2009) How does satisfaction translate into performance? An examination of commitment and cultural values. Hum Resour Dev Q 20:331-351

79. Zhang X, Bartol KM (2010) Linking empowering leadership and employee creativity: the influence of psychological empowerment, intrinsic motivation, and creative process engagement. Acad Manag J 53:107-128

\section{Publisher's Note}

Springer Nature remains neutral with regard to jurisdictional claims in published maps and institutional affiliations.

\section{Submit your manuscript to a SpringerOpen ${ }^{\circ}$ journal and benefit from:}

- Convenient online submission

- Rigorous peer review

- Open access: articles freely available online

- High visibility within the field

Retaining the copyright to your article

Submit your next manuscript at $\boldsymbol{\nabla}$ springeropen.com 